\title{
Leadership by Example: The Editorial Tenure of Dean Hess
}

Since its founding in 1956, RESPIRATORY CARE has been guided by five Editors, and I have had the pleasure of working with the last four: Phil Kittredge, Patricia Brougher, David Pierson, and Dean Hess. In the over 30 years that I have been honored to serve on the Editorial Board, the journey has occasionally been rough, but always moving forward. The Journal has grown most markedly in size and stature over the last decade. The success of a journal requires a dedicated team, thoughtful volunteer reviewers, an involved readership, and visionary leadership. Over the last decade, the vision of the Journal has emanated from thoughtful and unwavering eyes, peering out of Boston.

Dean Hess assumed the helm of Respiratory CARE on January 1, 2008, from David Pierson. Seven years before Hess became Editor, the Journal was accepted for inclusion in Index Medicus, ensuring stability and stature among a wider audience, both in the United States and abroad. Since 2008, many of the Journal's successes are obvious to readers. RESPIRATORY CARE received its first Impact Factor, submissions increased 5-fold, original research publications per month jumped by a factor of 4 , and online access flourished. RESPIRATORY CARE established a presence on Facebook and a voice on Twitter. Both manuscript submission and review were moved to a full online process. Invited reviews were established, and case reports were dropped. Other changes were indiscernible to readers but were no less important. The method by which copy editing was accomplished changed, speeding electronic publication; the Journal website changed appearance as well as its hosting site; and time required for editorial decisions steadily shortened. Collectively, these improvements can

Correspondence: Richard D Branson, University of Cincinnati, Department of Surgery, 231 Albert Sabin Way, ML \#0558, Cincinnati, OH 45267-0558. E-mail: branson@aarc.org.

DOI: $10.4187 /$ respcare. 05983 all be traced to the painstaking and strategic thinking of Dean Hess.

Editorship of a journal is a labor of love and passion. In 2018, Dean will transition from Editor to Managing Editor of the Journal, a move that ensures consistency for the Journal and comfort for the new Editor. Change is a constant in our lives, and a change in Editors is a time-honored tradition. Bringing fresh eyes and ideas to any endeavor can be transformative as it was when Dean Hess took over (what seems like) just a short time ago. My goal as the incoming Editor is to build on the innovations that Dean has implemented. In many ways then, outwardly, the goals and operation of the Journal will not change. We will strive for excellence and to be the leading voice in the respiratory care of patients. We will continue to publish high-quality clinical research and technology evaluations across the spectrum of respiratory care practice and pulmonary medicine. State of the art reviews and results of Journal Conference proceedings will remain a mainstay of the publication. As with my predecessor, future changes will consist of both the obvious and the indiscernible, but always with an eye toward enhancement.

I don't know that I can fully express my admiration and appreciation for the complete commitment Dean has given to the Journal. His steadfast guidance has benefited the profession, clinicians, researchers, and patients immeasurably. I have joked that taking over the reins from Dean is like taking over coaching his beloved Patriots from sure Hall of Fame coach Bill Belichick. The standards and expectations are stratospheric. I am confident that with his continued involvement, we will rise to the occasion.

Richard D Branson MSc RRT FAARC Editor in Chief RESPIRATORY CARE 